\title{
PENGARUH KEPEMIMPINAN TRANSFORMASIONAL, KEADILAN ORGANISASIONAL DAN KEPUASAN KERJA TERHADAP KOMITMEN ORGANISASIONAL
}

\author{
Putu Yoga Arimbawa ${ }^{1}$ \\ A. A. Sagung Kartika Dewi ${ }^{2}$ \\ ${ }^{1,2}$ Fakultas Ekonomi dan Bisnis Universitas Udayana, Bali, Indonesia \\ Email: yogaarimbawa594051@gmail.com
}

\begin{abstract}
ABSTRAK
Komitmen organisasional menjadi salah satu isu yang penting didalam dunia kerja, tidak dipungkiri komitmen organisasional dicantumkan dalam syarat dan kriteria dalam lowongan pekerjaan untuk memegang suatu posisi yang ditawarkan organisasi. Tujuan penelitian untuk menjelaskan pengaruh kepemimpinan transformasional, keadilan organisasional, dan kepuasan kerja terhadap komitmen organisasional. Penelitian ini dilakukan di Hotel Puri Saron Seminyak. Jumlah populasi yang diambil sebanyak 109 orang, dalam penelitian ini metode penentuan sampel yang digunakan menggunakan rumus slovin diperoleh hasil 52 orang. Pengumpulan data melalui data primer berupa kuesioner. Teknik analisis pada penelitian menggunakan metode regresi linier berganda dengan menggunakan variabel bebas kepemimpinan tranformasional, keadilan organisasional, dan kepuasan kerja. Berdasarkan hasil penelitian disimpulkan kepemimpinan transformasional berpengaruh positif serta signifikan terhadap komitmen organisasional karyawan Hotel Puri Saron Seminyak. Keadilan organisasional berpengaruh positif dan signifikan terhadap komitmen organisasional karyawan Hotel Puri Saron Seminyak. Serta kepuasan kerja berpengaruh positif serta signifikan terhadap komitmen organisasional karyawan Hotel Puri Saron Seminyak.
\end{abstract}

Kata kunci: kepemimpinan transformasional, keadilan organisasional, kepuasan kerja, komitmen organisasional.

\begin{abstract}
Organizational commitment is one of the important issues in the world of work. The purpose is to explain the effect of transformational leadership, organizational justice, and job satisfaction on organizational commitment. This research was conducted at Puri Saron Seminyak Hotel. Population is 109 people, in this study the method of determining the sample used using the formula slovin obtained results 52 people. Data collection is done through primary data in the form of questionnaires. The analysis technique used in this study uses multiple linear regression using independent variables of transformational leadership, organizational justice, and job satisfaction. Based on the results of this study, it can be concluded that transformational leadership has a positive and significant effect on the organizational commitment of Hotel Puri Saron Seminyak's employees. Organizational justice has a positive and significant effect on the organizational commitment of employees of Puri Saron Seminyak.
\end{abstract}

Keyword: transformational leadership, organizational justice, job satisfaction, organizational commitment. 
Putu Yoga Arimbawa, Pengaruh Kepemimpinan Transformasional...

\section{PENDAHULUAN}

Sumber daya manusia adalah komponen utama didalam seluruh kegiatan perusahaan. Organisasi tak akan mempunyai arti bila tidak ada SDM, karena didalam meraih tujuan serta suksesnya organisasi, SDM mempunyai fungsi penting didalam mengatur elemen-elemen yang terdapat didalam organisasi yaitu modal, teknologi juga uang (Indrawan dan Dewi, 2014). Memiliki sumber daya manusia yang berkualitas adalah sesuatu hal penting dalam penentu keberhasilan dari perusahaan. Perusahaan harus bisa mempertahankan karyawan-karyawan yang memiliki kopetensi baik agar perusahaan dapat mencapai tujuannya, salah satunya perusahaan yang bergerak di bidang perhotelan karena dalam dunia perhotelan yang diutamakan adalah kualitas pelayanan dari keterampilan karyawan dalam mengerjakan tugasnya.

Hotel Puri Saron Seminyak adalah industri di bidang jasa yang menawarkan peristirahatan kepada wisatawan mancannegara dan juga wisatawan domestik yang datang ke Bali. Hotel yang beralamatkan Jalan Camplung Tanduk, Seminyak, Kuta, Bali ini menawarkan kenyamanan dan keamanan bagi setiap pelanggannya. Hotel ini terdapat fasilitas pelayanan berupa spa, kolam berenang outdoor serta akomodasi lainnya. Kamar-kamarnya yang cerah dan lapang menampilkan dekorasi yang elegan, serta memiliki balkon pribadi yang menghadap taman hotel. Karyawannya ramah-ramah, baik dan peduli terhadap para tamu. Karyawan harus selalu mematuhi peraturan yang berlaku diperusahaan, mengerjakan pekerjaan sesuai SOP, mengembangkan pengetahuan dan keterampilan dengan program pelatihan, serta memberikan hasil yang terbaik bagi 
perusahaan merupakan bentuk dari komitmen karyawan yang diharapkan perusahaan.

Komitmen organisasional menjadi salah satu isu yang penting di dalam dunia kerja, tidak dipungkiri komitmen organisasional dicantumkan dalam syarat dan kriteria dalam lowongan pekerjaan untuk memegang suatu posisi yang di tawarkan organisasi. Banyak pemimpin perusahaan dan peneliti menyadari bahwa untuk bisa bersaing secara efektif di pasar, perusahaan perlu mempertahankan karyawan dan memperkecil keinginan karyawan untuk meninggalkan pekerjaannya (Naqvi et al., 2013). Keahlian perusahaan didalam mengatur pegawai yang dilaksanakan secara bagus, dapat menyebabkan komitmen yang tinggi dari pegawai pada perusahaan. Dikarenakan hal tersebut maka pihak manajemen haruslah mampu memiliki upaya memberi peningkatan kinerja pegawai menggunakan segala cara, salah satunya yaitu seperti memberikan penanaman komitmen pegawainya pada perusahaan. (Surya dan Rendy, 2013).

Berdasarkan wawancara awal terhadap 10 karyawan Hotel Puri Saron Seminyak, 7 diantaranya memiliki komitmen organisasional yang masih rendah diakibatkan oleh kepemimpinan transformasional, keadilan organisasional dan kepuasan kerja. Hal tersebut diketahui dari karyawan merasa belum adanya keterbukaan antara sesama rekan kerja dan juga pimpinan di lingkungan perusahaan, presepsi dari karyawan bahwa masih banyak perusahaan serupa yang memberikan pengahasilan yang lebih besar dari perusahaan tempatnya bekerja, karyawan tidak masalah meniggalkan dan berpindah ke perusahaan lain jika kebetuhan mereka tidak terpenuhi. Hal ini tentunya dapat berdampak buruk bagi 
Putu Yoga Arimbawa, Pengaruh Kepemimpinan Transformasional...

perusahaan karena mengganggu keefektivitasan karyawan dalam pekerjaan Komitmen karyawan di Hotel Puri Saron Seminyak harus menjadi hal yang diperhatikan oleh pihak manajemen. Demi terciptanya suasana kerja yang kondusif, tentu saja perlunya keseriusan dan komitmen dari karyawan dalam menjalankan pekerjaannya demi terciptanya tujuan perusahaan.

Kepemimpinan transformasional didefinisikan sebagai pemimpin yang mengubah nilai, kebutuhan aspirasi, prioritas pengikut dan juga memotivasi pengikut mereka untuk bekerja melebihi ekspetasi yang diberikan kepada mereka (Thamrin, 2012). Hidayat (2013) menjabarkan pegawai yang memberi penilaian pemimpin mereka mempunyai praktek kepemimpinan yang jelek dapat menimbulkan seseorang pegawai mempunyai kencendrungan yang lebih besar untuk resign ataupun menurunkan komitmen pegawai pada perusahaan. Penelitian yang dilakukan Khan et al. (2013) menemukan hasil bahwa kepemimpinan transformasional berpengaruh positif terhadap komitmen organisasional.

Fenomena yang terjadi terkait kepemimpinan transformasional dimana pemimpin belum bisa mengarahkan dan menumbuhkan sikap kreatif terhadap karyawan di dalam bekerja. Masih adanya ketidakseriusan dari karyawan dalam menyelesaikan pekerjaan karena karyawan masih menunggu instruksi dari pimpinan untuk melaksanakan dan menyelesaikan permasalahan yang timbul di dalam pekerjaannya. Hal tersebut menjadi indikasi masih rendahnya kepemimpinan transformasional di Hotel Puri Saron Seminyak dan jika hal ini berlangsung terus menerus akan menurunkan dan menghambat kegiatan di perusahaan. 
Selain indikasi rendahnya kepemimpinan transformasional, karyawan juga merasa keadilan belum berjalan dengan baik. Fenomena yang terjadi terkait keadilan organisasional disebabkan oleh tidak adanya kesempatan bagi karyawan di dalam mengemukakan pendapatnya di dalam pengambilan keputusan dan karyawan merasa hak-haknya tidak terpenuhi oleh perusahaan. Karyawan berprestasi masih mengeluhkan pemberian reward yang diterima sama dengan karyawan lainnya, dalam kenyataannya karyawan berpretasi memerlukan upaya yang lebih besar dari pada karyawan yang kurang berprestasi. Hal ini dapat menyebabkan karyawan merasa dirugikan karena hak-hak dari setiap karyawan diabaikan oleh perusahaan dan mengakibatkan menurunya komitmen dari karyawan.

Kepuasan adalah sikap umum terhadap pekerjan seseorang yang menunjukan perbedaan antara jumlah pengahargaan yang dietrima pekerja dan jumlah yang mereka yakini seharusnya diterima. Seseorang yang memiliki tingkat kepuasan yang tinggi akan memberikan dampak yang positif terhadap pekerjaannya. Tetapi, seseorang yang dikatakan tidak puas terhadap pekerjaannya akan memberikan dampak yang negatif terhadap pekerjaannya (Wibowo, 2011:501). Penelitian yang dilakukan Karim dan Rehman (2012) menunjukan bahwa kepuasan kerja mampu mempengaruhi komitmen organisasional secara positif. Fenomena yang muncul terkait kepuasan kerja karyawan Hotel Puri Saron Seminyak dimana, kerja sama tim yang kurang kondusif, tidak adanya kesempastan untuk mengembangkan karir, dan kurangnya perhatian yang dirasakan karyawan dari atasan. Hal ini dapat memicu menurunnya kepuasan 
Putu Yoga Arimbawa, Pengaruh Kepemimpinan Transformasional...

kerja dari setiap karyawan dan akan mengakibatkan rendahnya komitmen karyawan tersebut.

Berdasarkan latar belakang dan masalah yang terdapat di Hotel Puri Saron Seminyak, maka dilakukan penelitian mengenai "Pengaruh Kepemimpinan Tranformasional, Keadilan Organisasional, Dan Kepuasan Kerja Terhadap Komitmen Organisasional (Studi Pada Karyawan Hotel Puri Saron Seminyak)”. Berdasar kepada latar belakang yang sudah disampaikan, jadi rumusan masalah dalam penelitian berikut yaitu: 1) Bagaimanakah pengaruh kepemimpinan transformasional pada komitmen organisasional pegawai Hotel Puri Saron Seminyak ? 2) Bagaimanakah pengaruh keadialan organisasional terhadap komitmen organisasional pegawai Hotel Puri Saron Seminyak ? 3) Bagaimanakah pengaruh kepuasan kerja terhadap komitmen organisasional pegawai Hotel Puri Saron Seminyak ? Berdasar pada rumusan masalah yang sudah disampaikan, maka yang menjadi tujuan dari penelitian berikut yaitu: 1) Untuk mengetahui pengaruh variabel kepemimpinan transformasional terhadap komitmen organisasional karyawan Hotel Puri Saron Seminyak. 2) Untuk mengetahui pengaruh variabel keadialan organisasional terhadap komitmen organisasional karyawan Hotel Puri Saron Seminyak. 3) Untuk mengetahui pengaruh variabel kepuasan kerja terhadap komitmen organisasonal karyawan Hotel Puri Saron Seminyak. 


\section{Gambar 1. Kerangka Konseptual}

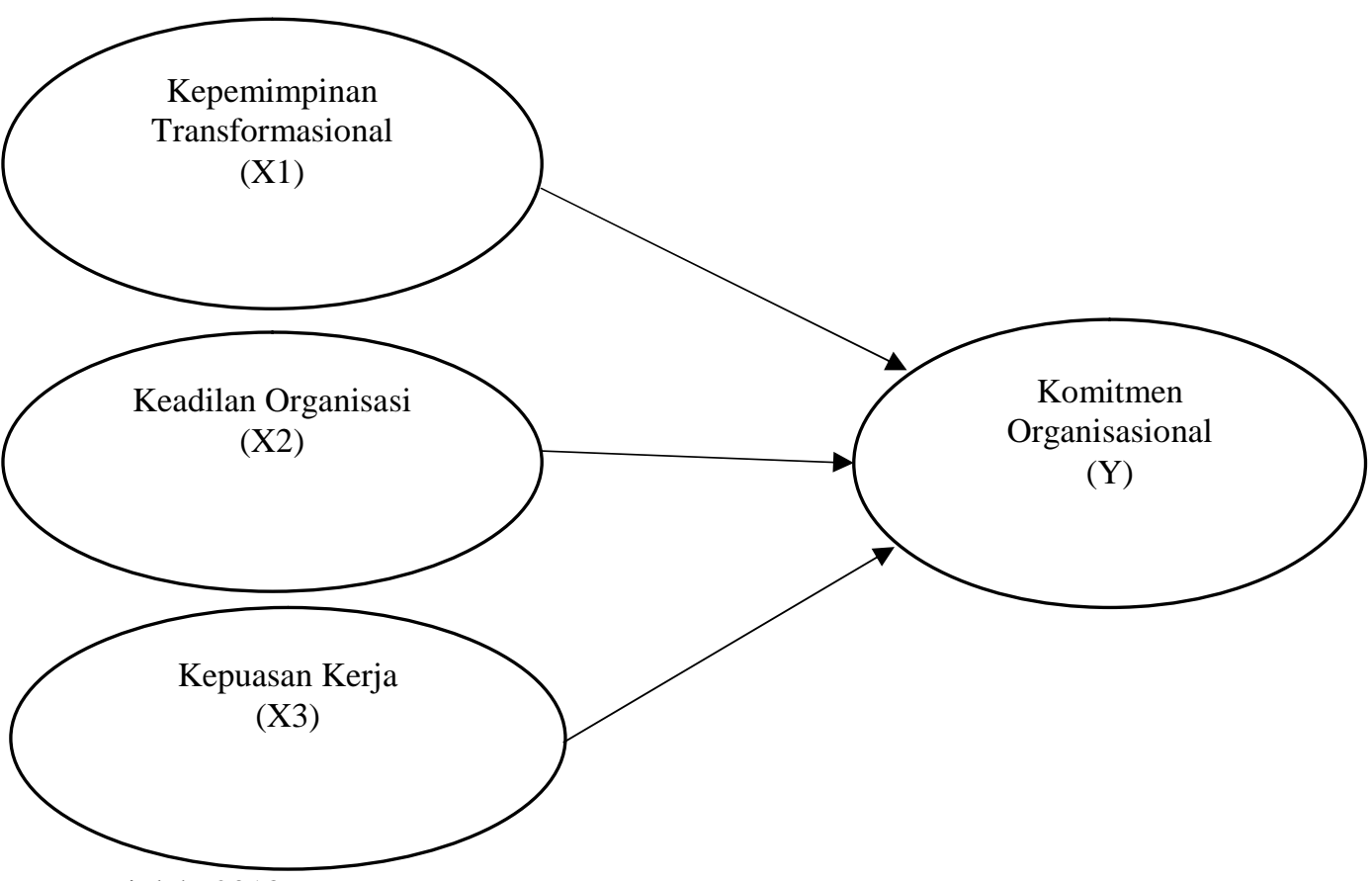

Sumber: Data Diolah, 2018

Keberhasilan perusahaan didalam memperoleh tujuannya juga sasaran bergantung seseorang pimpinan mengadopsi gaya kepemimpian yang cocok hingga bisa memberi pengaruh komitmen (Voon et al., 2015). Karyawan yang bekerja dengan pemimpin transformasional akan merasa lebih terlibat dan berkomitmen untuk organisasi mereka (Mahmet, 2014). Terdapat pengaruh yang signifikan antara variabel kepemimpinan transformasional terhadap komitmen organisasional. Penelitiannya menemukan hasil dimana kepemimpinan transformasional memiliki pengaruh terhadap komitmen organisasi karena kepemimpinan transformasional lebih memberikan perhatian, dorongan motivasi dan mampu memahami keinginan karyawannya. (Desianty, 2015).

Penelitian Njoroge et al. (2015) mendapatkan hasil bahwasannya kepemimpinan transformasional mempunyai pengaruh positif pada komitmen 
organisasional. Dikatakan dalam penelitiannya kepemimpinan transformasional perlu diperhatikan guna meningkatkan komitmen organisasional. Khan et al. (2013) menyatakan bahwa kepemimpinan transformasional berpengaruh positif terhadap komitmen organisasional. Kepemimpinan transformasional memainkan peranan besar dalam komitmen organisasional. Pemimpin memilih cara inovatif dalam memimpin karyawannya dan pemimpin mampu memberikan contoh yang baik, maka para karyawan akan berupaya meningkatkan komitmen mereka. Bushra et al. (2013) juga memberi pernyataan bahwasannya kepemimpinan transformasional berpengaruh positif terhadap komitmen organisasional. Dunn et al. (2012) dalam penelitiannya terhadap organisasi di AS dan Israel menemukan hasil yang mendukung bahwa perilaku pemimpin transformasional secara positif dan signifikan memiliki hubungan dengan komitmen organisasional. Berdasarkan uraian hasil penelitian terdahulu bisa dilanjutkan hipotesis seperti berikut:

$\mathrm{H}_{1}$ : Kepemimpinan transformasional berpengaruh positif dan signifikan terhadap komitmen organisasional.

Keadilan organisasi memiliki peranan vital didalam mengembangkan komitmen organisasi. pegawai yang diperlakukan secara adil didalam perusahaan lebih memiliki komitmen dengan pekerjaannya dibandingkan dengan pegawai yang tak diberakukan secara adil dan mereka akan condong dalam berpindah ke perusahaan lain (Bakhshi et al., 2013). (Jawad et al., 2012) menyatakan saat pimpinan memulai memiliki urusan dengan bawahannya melalui cara yang adil serta amanah, jadi komitmen karyawan bisa mendapat peningkatan. Jawad et al. (2012) didalam penelitian yang mempunyai judul Role of Organizational justice in organizational commitment with moderating effect of employee work attitudes 
bahwasannya ada pengaruh yang signifikan diantara keadilan distributif, prosedural serta keadilan interaksional pada komitmen organisasional. Berdasar hal tersebut memberi kekuatan hubungan yang menampilkan petunjuk ada atau tidaknya pengaruh keadilan organisasional pada komitmen organisasional.

Penelitian yang dilakukan oleh Akanbi et al. (2013) pada salah satu organisasi multinasional di Nigeria dengan 215 sampel mendapatkan hasil bahwasannya keadilan organisasional mempunyai pengaruh positif serta signifikan terhadap komitmen organisasional. Bakhsi et al. (2013) menyatakan hasil dari penelitiannya bahwa dengan adanya keadilan organisasi terlebih untuk keadilan distributif dan prosedural dapat mempengaruhi komitmen organisasi secara signifikan. Dehkordi et al. (2013) mendapatkan bahwasannya keadilan organisasional memiliki pengaruh positif pada komitmen organisasional. Tidak adanya keadilan organisasi dapat menimbulkan komitmen yang kecil. Penelitian sebelumnya yang dilakukan Crow et al. (2012), menemukan bahwa tingkat keadilan organisasional memiliki hubungan yang positif dengan komitmen organisasional. Berdasarkan uraian hasil penelitian terdahulu dapat dilanjutkan hipotesis sebagai berikut.

$\mathrm{H}_{2}$ : Keadilan organisasional berpengaruh positif dan signifikan terhadap komitmen organisasional.

Sumber daya manusia yang setia, puas, sesuai dengan tujuan dan nilai-nilai organisasi dan cenderung untuk mempertahankan keanggotaan organisasi dapat menjadi faktor penting dalam efektivitas organisasi. Hal tersebut menujukan jika karyawan merasa terpuasan dengan pekerjaannya sekarang maka, karyawan akan lebih berkomitmen dan enggan untuk meninggalkan organisasinya (Ghaziani et 
al., 2012). Hasil penelitian dari Karim dan Rehman (2012) menunjukan kolerasi yang kuat antara komitmen organisaional dengan kepuasan kerja. Sebagai karyawan yang puas cenderung akan lebih setia kepada organisasinya. Karyawan tidaklah memungkinkan untuk merubah kerjaan mereka serta memberi anggapan kerjaan mereka ada yang melebihi daripada yang lainnya. Manajer perusahaan haruslah memberi kepastian bahwasannya pegawai mempunyai tingkat kepuasan kerja yang besar didalam rangka agar memberi peningkatan tingkat komitmen pegawai. Karakus et al. (2014) mendapatkan hasil pada kepuasan kerja mempunyai pengaruh positif serta signifikan pada komitmen organisasional. Shurbagi (2014) mendapatkan hasil bahwasannya kepuasan kerja mempunyai pengaruh positif juga signifikan terhadap komitmen organisasional.

Pradhiptya (2013) meyatakan bahwa kepuasan kerja berpengaruh positif dan signifikan terhadap komitnmen organisasi. Lumley (2014) menyimpulkan kepuasan kerja mempengaruhi sikap masyarakat terhadap pekerjaan dan berbagai aspek pekerjaan mereka, kepuasan kerja dipengaruhi oleh pribadi yang menyebabkan reaksi emosional yang mempengaruhi komitmen organisasi. Berdasarkan uraian hasil penelitian dahulu dapat dilanjutkan hipotesis sebagai berikut.

$\mathrm{H}_{3}$ : Kepuasan kerja berpengaruh positif dan signifikan terhadap komitmen organisasional.

\section{METODE PENELITIAN}

Penelitian ini akan menjelaskan antara variabel kepemimpinan transformasional, keadilan organisasional dan kepuasan kerja terhadap komitmen organisasional karyawan di Hotel Puri Saron Seminyak. Lokasi penelitian ini 
dilakukan di Hotel Puri Saron Seminyak yang beralamat di Jalan Camplung Tanduk Seminyak, Kuta-Bali. Dijadikannya perusahaan ini sebagai lokasi penelitian karena adanya permasalahan mengenai komitmen organisasional pada karyawan menjadi alasan peneliti memilih Hotel Puri Saron Seminyak sebagai lokasi penelitian. Subyek penelitian ini adalah Karyawan Hotel Puri Saron Seminyak. Obyek penelitian ini, yaitu kepemimpinan transformasional, keadilan organisasional, kepuasan kerja, dan komitmen organisasional.

Variabel terikat (dependent variable) adalah variabel yang memiliki ketergantungan dari variable lainnya. Variabel terikat didalam penelitian berikut yaitu Komitmen Organisasional (Y). Variabel bebas (independent variable) adalah variable yang bisa memberi pengaruh variable lain. Variabel bebas dalam penelitian ini adalah Kepemimpinan Transformasional (X1), Keadilan Organisasional (X2) dan Kepuasan Kerja (X3). Komitmen organisasional dapat diartikan sebagai sikap karyawan yang setia, keinginan yang kuat untuk bertahan dan memiliki rasa keberpihakan penuh dengan Hotel Puri Saron Seminyak dengan menunjukkan sikap bekerja keras demi tercapainya tujuan Hotel Puri Saron Seminyak. Indikator yang dapat digunakan dalam menkurur komitmen organisasional dari instrumen yang dikembangkan Meyer dan Allen (1991) antara lain. 1) Komitmen afektif (affective commitment) 2) Komitmen berkelanjutan (continuance commitment) 3) Komitmen normatif (normative commitment).

Kepemimpinan transformasional dapat diartikan sebagai gaya kepemiminan yang mampu mempengaruhi karyawan Hotel Puri Saron Seminyak dengan memberikan dorongan berupa motivasi yang dimana pemimpin dapat 
Putu Yoga Arimbawa, Pengaruh Kepemimpinan Transformasional...

mengembangkan ikatan emosional yang baik dengan karyawan Hotel Puri Saron Seminyak sehingga memberikan perubahan yang baik dan mewujudkan dari visi dan tujuan yang diinginkan oleh pimpinan Hotel Puri Saron Seminyak. Indikator kepemimpinan transformasional sebagai berikut (Ismail, et al., 2013). 1) Individualized influence (pengaruh ideal) 2) Inspirational motivation (motivasi inspirasional) 3) Intellectual stimulation (stimulasi intelektual) 4) Individualized consideration (pertimbangan individual).

Keadilan organisasional dapat diartikan tingkat kesetaraan mengenai keputusan-keputusan yang diambil oleh pimpinan Hotel Puri Saron Seminyak yang diharapkan oleh setiap karyawan. Al-Zu'bi (2013) menyatakan bahwa keadilan organisasional terdiri atas tiga bagian yang bisa digunakan sebagai indikator yaitu keadilan distributif, keadilan prosedural, dan keadilan interaksional. Kepuasan kerja dapat diartikan sebagai penilaian dari karyawan Hotel Puri Saron Seminyak tentang pekerjaannya yang menimbulkan perasaan senang yang dirasakan karyawan di tempat kerja karena keingan dari karyawan terpenuhi sehingga karyawan semakin mencintai pekerjaannya. Mengacu pada penelitian Puspitawati dan Riana (2014) indikator yang digunakan untuk kepuasan kerja antara lain beban kerja, gaji, kenaikan jabatan, pengawasan dan rekan kerja.

Penelitian ini yang menjadi populasi adalah seluruh karyawan Hotel Puri Saron Seminyak. Ukuran populasi penelitian ini sejumlah 109 orang, sedangkan pimpinan Hotel Puri Saron Seminyak tidak termasuk dalam responden penelitian. Jumlah karyawan tetap yang dimiliki Hotel Puri Saron terdapat dalam tabel berikut. Metode penentuan sampel penelitian ini dengan menggunakan rumus 
Slovin. Berdasarkan perhitungan rumus slovin jumlah sampel yang diteliti yaitu 52 karyawan. Metode penentuan sampel menggunakan teknik proportional random sampling karena mengambil sampel dari setiap divisi dalam organisasi secara proporsional sesuai dengan jumlah karyawan dalam penelitian sehingga dapat mewakili seluruh populasi yang ada.

Tabel 1.

Jumlah Karyawan

\begin{tabular}{lc}
\hline \multicolumn{1}{c}{ Divisi } & Jumlah Karyawan \\
\hline Accounting & 16 \\
Sales & 5 \\
Housekeeping & 22 \\
Front Office & 17 \\
Engineering & 11 \\
Human resources \& security & 9 \\
FB. Service & 15 \\
FB. Kitchen $\quad$ Jumlah & 14 \\
\hline \multicolumn{2}{c}{ Sumber : Hotel Puri Saron Seminyak, 2017 }
\end{tabular}

Tabel 2 menjelaskan hasil perhitungan dari proporsi jumlah sampel dalam penyebaran kuesioner di Hotel Puri Saron Seminyak.

Tabel 2.

Proporsi Jumlah Sampel

\begin{tabular}{cccc}
\hline Divisi & Populasi & Total Populasi & Sampel \\
& & & \\
\hline Accounting & 16 & 0,146 & 8 \\
Sales & 5 & 0,045 & 2 \\
Housekeeping & 22 & 0,201 & 11 \\
Front Office & 17 & 0,155 & 8 \\
Engineering & 11 & 0,1 & 5 \\
Human resources \& security & 9 & 0,082 & 4 \\
FB. Service & & & 7 \\
FB. Kitchen & 15 & 0,137 & 7 \\
\hline Jumlah & 14 & 0,128 & 52 \\
\hline Sumber: Data Diolah, 2018 & 109 & & \\
\hline
\end{tabular}


Putu Yoga Arimbawa, Pengaruh Kepemimpinan Transformasional...

Metode kuesioner merupakan metode pengumpulan data dengan memakai daftar pernyataan yang disebar ke responden tentang kepemimpinan transformasional, keadilan organisasional, kepuasan kerja dan komitmen organisasional karyawan Hotel Puri Saron Seminyak. Pengukuran variabel dilakukan dengan skala likert. Data kualitatif yang dipakai didalam riset berikut yaitu gambaran umum, struktur serta sejarah Hotel Puri Saron Seminyak. Data kuantitatif yang dipakai didalam riset berikut yaitu jumlah pegawai yang bekerja di Hotel Puri Saron Seminyak serta hasil kuesioner yang bentuknya jawaban responden yang terukur dengan skala Likert mengenai variable yang dimaksudkan adalah kepemimpinan transformasional, keadilan organisasional, kepuasan kerja dan komitmen organisasional di Hotel Puri Saron Seminyak.

Analisis linier regresi digunakan untuk menganalisis suatu variabel terikat yang dipengaruhi lebih dari satu variabel bebas. Analisis regresi linier berganda ini digunakan untuk tujuan penelitian yaitu menganalisis pengaruh kepemimpinan trasformasional, keadilan organisasional, kepuasan kerja, komitmen organisasional di Hotel Puri Saron Seminyak. Digunakan program SPSS dalam menganalisis data dengan model regresi linier berganda yang digunakan yaitu sebagai berikut:

$$
Y=\alpha+\beta_{1} X_{1}+\beta_{2} X_{2}+\beta_{3} X_{3}+\varepsilon
$$

Keterangan :

$\mathrm{Y}=$ Komitmen Organisasional

$\alpha \quad=$ Konstanta

$\beta_{1} \cdot \beta_{2} \cdot \beta_{3}=$ Koefisien regresi variabel $X_{1} \cdot X_{2} \cdot X_{3}$

$\mathrm{X}_{1} \quad=$ Kepemimpinan Transformasional

$\mathrm{X}_{2} \quad=$ Keadilan Organisasional

$\mathrm{X}_{3} \quad=$ Kepuasan Kerja

$\varepsilon \quad=$ Komponen residual atau eror 


\section{HASIL DAN PEMBAHASAN}

Karakter responden adalah data responden yang terkumpul agar diketahuinya profil responden riset. Dari hasil penelitian yang dilaksanakan pada pegawai di Hotel Puri Saron Seminyak, dapat diketahui gambaran tentang karakteristik responden yang meliputi tiga aspek yaitu umur, jenis kelamin, pendidikan terakhir dan lama bekerja.

Tabel 3.

Karakteristik Responden

\begin{tabular}{cllcc}
\hline No & Karakteristik & & Jumlah & Persentase \\
\hline 1 & Umur & 18-20 Tahun & 10 & 19.02 \\
& & 21-30 Tahun & 21 & 40.04 \\
& & 31-39 Tahun & 17 & 32.07 \\
& & & & \\
& & >40 Tahun & 4 & 07.07 \\
& & Total & $\mathbf{5 2}$ & $\mathbf{1 0 0}$ \\
\hline 2 & \multirow{2}{*}{ Jenis Kemlamin } & Laki-Laki & 37 & 71.01 \\
& & Perempuan & 15 & 28.09 \\
& & Total & $\mathbf{5 2}$ & $\mathbf{1 0 0}$ \\
\hline 3 & Pendidikan & SMA/SMK & 18 & 34.07 \\
& & Diploma & 24 & 46.01 \\
& & Sarjana (S1) & 10 & 19.02 \\
& & Total & $\mathbf{5 2}$ & $\mathbf{1 0 0}$ \\
\hline 4 & Masa Kerja & < 1 Tahun & 10 & 19.02 \\
& & 1-5 Tahun & 23 & 44.02 \\
& & > 5 Tahun & 19 & 36.06 \\
& & Total & $\mathbf{6 0}$ & $\mathbf{1 0 0}$ \\
\hline
\end{tabular}

Sumber: Data Diolah, 2018

Responden dengan umur 18-20 tahun sebanyak 10 orang (19,2 persen), responden dengan umur 21-30 tahun sebanyak 21 orang (40,4 persen), responden dengan umur 31-39 tahun sebanyak 17 orang (32,7 persen), responden dengan umur $>40$ tahun sebanyak 4 orang $(7,7$ persen). Hal ini berarti bahwa, mayoritas karyawan di Hotel Puri Saron Seminyak rata-rata berumur 21-30 tahun dimana pihak manajemen Hotel Puri Saron Seminyak bermaksud untuk meberdayakan tenaga kerja yang energik, berpenampilan menarik dan sudah memiliki 
Putu Yoga Arimbawa, Pengaruh Kepemimpinan Transformasional...

pengalaman kerja sehingga pengunjung hotel merasakan pelayanan yang maksimal dan merasa nyaman dan senang. Sebagian besar responden yaitu 58,2 persen adalah laki-laki dan 41,8 persen adalah perempuan, ini berarti sistem manajemen Hotel Puri Saron Seminyak lebih membutuhkan karyawan laki-laki karena berkaitan dengan jenis pekerjaan yang ada.

Sebagian besar responden yaitu 46,1 persen responden sebanyak 24 orang berpendidikan Diploma, 34,7 persen sebanyak 18 orang berpendidikan SMA/SMK, 19,2 persen sebanyak 10 orang berpendidikan Sarjana (S1), hal tersebut mengindikasikan bahwa mayoritas responden di Hotel Puri Saron Seminyak berpendidikan Diploma yang memiliki keahlian dan keterampilan sesuai bidangnya terutama dibidang perhotelan. Responden dengan masa kerja $<1$ tahun sebanyak 10 orang (19,2 persen), responden dengan masa kerja 1-5 tahun sebanyak 23 orang (44,2 persen), dan responden dengan masa kerja $>5$ tahun sebanyak 23 orang (44,2 persen). Hal tersebut menunjukan bahwa mayoritas responden di Hotel Puri Saron Seminyak memiliki masa kerja selama 1-5 tahun.

Suatu instrumen dikatakan valid apabila memiliki koefisien korelasi antara butir dengan skor total dalam instrumen tersebut lebih besar dari 0,30 dengan tingkat kesalahan Alpha 0,05. Hasil uji validitas pada tabel memberi petunjuk bahwasannya semua instrumen penelitian yang dipakai dalam pengukuran variabel kepemimpinan transformasional, keadilan organisasi, kepuasan kerja, dan komitmen organisasional mempunyai nilai koefisien korelasi dengan skor total semua item pernyataan lebih tinggi daripada 0,30 dengan signifikansi kurang daripada 0,05. Hasil tersebut memberi petunjuk bahwasannya butir-butir 
pernyataan didalam instrumen penelitian itu valid serta dapat dipakai sebagai instrumen penelitian. Nilai Alpha Cronbach dapat dikatakan reliabel apabila nilainya lebih tinggi ataupun sama dengan 0,60. Rekapitulasi hasil uji reliabilitas instrumen penelitian bisa terlihat di Tabel 4 berikut.

Tabel 4.

Hasil Uji Reliabilitas

\begin{tabular}{cccc}
\hline No. & Variabel & $\begin{array}{c}\text { Cronbach's } \\
\text { Alpha }\end{array}$ & Keterangan \\
\hline $\mathbf{1}$ & Kepemimpinan Transformasional & 0,776 & Reliabel \\
$\mathbf{2}$ & $\left(\mathrm{X}_{1}\right)$ & 0,798 & Reliabel \\
$\mathbf{3}$ & Keadilan Organisasi $\left(\mathrm{X}_{2}\right)$ & 0,786 & Reliabel \\
$\mathbf{4}$ & Kepuasan Kerja $\left(\mathrm{X}_{3}\right)$ & 0,734 & Reliabel \\
\hline Sumber: & Komitmen Organisasional $(\mathrm{Y})$ & &
\end{tabular}

Hasil uji reliabilitas yang tersaji didalam Tabel 4 memberi petunjuk bahwasannya semua instrument penelitian mempunyai koefisien Cronbach's Alpha lebih dari 0,60. Sehingga bisa dinyatakan bahwasannya semua variabel sudah memenuhi syarat reliabilitas ataupun kehandalan jadi bisa dipakai dalam pelaksanaan penelitian.

Jawaban responden mengenai kepuasan kerja memperoleh nilai rata-rata sebesar 3.20 dan masuk dalam kriteria cukup tinggi. Hal tersebut menunjukkan bahwa karyawan di Hotel Puri Saron Seminyak telah merasa menjadi bagian keluarga organisasi. Nilai rata-rata tertinggi jawaban responden ditunjukkan pada pernyataan "Saya merasa menjadi bagian keluarga di organisasi ini”" sebesar 4,02. Selanjutnya, nilai rata-rata terendah jawaban responden ditunjukkan pada pernyataan "Saya memiliki kewajiban dan tanggungjawab untuk tetap bertahan dalam organisasi ini" dengan nilai rata-rata sebesar 2,92. Jawaban responden 
Putu Yoga Arimbawa, Pengaruh Kepemimpinan Transformasional...

mengenai kepemimpinan transformasional memperoleh nilai rata-rata sebesar 3.81 dan masuk dalam kriteria baik. Hal tersebut menunjukkan bahwa pemimpin di Hotel Puri Saron Seminyak telah mampu menyampaikan tujuan organisasi dengan jelas. Nilai rata-rata tertinggi jawaban responden ditunjukkan pada pernyataan "Pimpinan mampu menyampaikan tujuan organisasi dengan jelas" sebesar 3,96. Selanjutnya, nilai rata-rata terendah jawaban responden ditunjukkan pada pernyataan "Pemimpin mampu membangkitkan kreatifitas bawahan dalam melakukan pekerjaan" dengan nilai rata-rata sebesar 3.60.

Jawaban responden mengenai keadilan organisasional memperoleh nilai rata-rata sebesar 3.78 dan masuk dalam kriteria baik. Hal tersebut menunjukkan bahwa keadilan organisasional di Hotel Puri Saron Seminyak telah dilakukan dengan baik. Nilai rata-rata tertinggi jawaban responden ditunjukkan pada pernyataan "Prosedur kerja yang dilaksanakan sudah diterapkan secara adil" sebesar 4,00. Selanjutnya, nilai rata-rata terendah jawaban responden ditunjukkan pada pernyataan "Perusahaan memberikan kesempatan yang sama bagi karyawan untuk ikut dalam pengambilan keputusan" dengan nilai rata-rata sebesar 3,48. Jawaban responden mengenai kepuasan kerja memperoleh nilai rata-rata sebesar 3.80 dan masuk dalam kriteria tinggi. Hal tersebut menunjukkan bahwa karyawan di Hotel Puri Saron Seminyak telah merasa puas akan kinerjanya. Nilai rata-rata tertinggi jawaban responden ditunjukkan pada pernyataan "Hubungan saya dengan rekan kerja sudah terjalin dengan baik" sebesar 3,96. Selanjutnya, nilai rata-rata terendah jawaban responden ditunjukkan pada pernyataan "Saya merasa 
puas dengan atasan saya dalam menangani masalah yang dihadapi karyawannya" dengan nilai rata-rata sebesar 3,48.

Penelitian ini menggunakan teknik analisis regresi berganda dalam pengujian data. Tujuan dari analisis regresi linear berganda untuk mengetahui ketergantungan suatu variabel terikat dengan satu atau lebih variabel bebas. Perhitungan koefisien regresi linier berganda dilakukan dengan analisis regresi melalui software SPSS 18.0 for Windows, diperoleh hasil yang ditunjukan pada Tabel 5.

Tabel 5.

Hasil Analisis Regresi Linier Berganda

\begin{tabular}{|c|c|c|c|c|c|c|}
\hline Model & $\begin{array}{l}\text { Unstandar } \\
\text { Coefficien }\end{array}$ & $\begin{array}{l}\text { lized } \\
\text { s }\end{array}$ & $\begin{array}{l}\text { Standardized } \\
\text { Coefficients }\end{array}$ & & $\mathrm{t}$ & Sig \\
\hline (Constant) & B 3,178 & $\begin{array}{r}\text { Std. Error } \\
2,275\end{array}$ & Beta & & 1,397 & 0,169 \\
\hline $\begin{array}{l}\text { Kepemimpinan } \\
\text { Transformasional }\end{array}$ & 0,369 & 0,133 & & 0,342 & 2,775 & 0,008 \\
\hline Keadilan Organisasional & 0,198 & 0,084 & & 0,293 & 2,37 & 0,022 \\
\hline Kepuasan Kerja & 0,31 & 0,136 & & 0,265 & 2,29 & 0,026 \\
\hline R Square & $\mathbf{0 , 5 5 2}$ & & & & & \\
\hline Adjusted R Square & $\mathbf{0 , 5 2 4}$ & & & & & \\
\hline F Statistik & 19,716 & & & & & \\
\hline Signifikansi Uji F & $\mathbf{0}$ & & & & & \\
\hline
\end{tabular}

Berdasar pada hasil analisis regresi linier berganda seperti yang tersaji di Tabel 5, jadi bisa dibuat persamaan regresi sebagai berikut:

$$
\mathrm{Y}=3,178+0,369 \mathrm{X}_{1}+0,198 \mathrm{X}_{2}+0,310 \mathrm{X}_{3}
$$

Berdasarkan persamaan diatas, maka variabel kepemimpinan transformasional, keadilan organisasional, dan kepuasan kerja memiliki pengaruh positif yang signifikan pada variabel komitmen organisasional karyawan di Hotel 
Puri Saron Seminyak. 1) $\beta 1=0,369$ memiliki arti pengaruh kepemimpinan transformasional (X1) memberi akibat meningkatnya komitmen organisasional (Y) pegawai, dengan asumsi variabel bebas yang lain dianggap konstan. 2) $\beta 2=$ 0,198 memiliki arti pengaruh keadilan organisasional (X2) memberi akibat meningkatnya komitmen organisasional (Y) pegawai, dengan berasumsi variabel bebas yang lain dianggap konstan. 3) $\beta 3=0,310$ memiliki arti pengaruh kepuasan kerja (X3) memberi akibat meningkatnya komitmen organisasional (Y) pegawai, dengan berasumsi variabel bebas lain dianggap konstan.

Besarnya pengaruh variabel bebas terhadap variabel terikat yang ditunjukkan oleh nilai determinasi total (R Square) sebesar 0,552 mempunyai arti bahwa sebesar 55,2 persen variasi Komitmen Organisasional karyawan Hotel Puri Saron Seminyak dipengaruhi oleh variasi Kepemimpinan Transformasional, Keadilan Organisasi, dan Kepuasan Kerja, sedangkan sisanya sebesar 44,8 persen djelaskan oleh faktor lain yang tidak dimasukkan ke dalam model. Dalam pengujian apa data yang dipakai normal ataupun tidaknya bisa dilaksanakan dengan pengujian Kolmogorov Smirnov. Bila koefisien Asymp. Sig. (2-tailed) lebih tinggi dari 0,05 jadi data itu disebut memiliki distribusi normal.

Tabel 6.

Hasil Uji Normalitas

\begin{tabular}{cc}
\hline & Unstandardized \\
\hline $\mathrm{N}$ & 52 \\
Kolmogorov-Smirnov Z & 0,601 \\
Asymp. Sig. (2-tailed) & 0,862 \\
\hline
\end{tabular}

Sumber: Data Diolah, 2018

Tabel 6 menunjukan bahwasannya nilai Kolmogorov Smirnov sejumlah 0,601, sedang nilai Asymp. Sig. (2-tailed) sejumlah 0,862. Hasil itu memberi 
indikasi bahwasannya model persamaan regresi itu memiliki distribusi normal dikarenakan nilai Asymp. Sig. (2-tailed) 0,862 lebih tinggi daripada nilai alpha 0,05 .

Tabel 7.

Hasil Uji Multikoleniaritas

\begin{tabular}{lcc}
\hline \multicolumn{1}{c}{ Variabel } & Tolerance & VIF \\
\hline Kepemimpinan Transformasional & 0,613 & 1,631 \\
Keadilan Organisasional & & \\
Kepuasan Kerja & 0,613 & 1,632 \\
\hline
\end{tabular}

Sumber: Data Diolah, 2018

Ada atau tidaknya multikolinearitas bisa terlihat dilihat dari nilai tolerance ataupun variance inflation factor (VIF). Apabila nilai tolerance lebih tinggi darpada 10 persen ataupun VIF kurang daripada 10, jadi dapat diketahui bahwa tak adanya multikolinearitas. Tabel 7 menunjukan bahwasannya nilai tolerance serta VIF daripada Variabel Kepemimpinan Transformasional, Keadilan Organisasional, dan Kepuasan Kerja. Besaran itu memberi petunjuk bahwasannya nilai tolerance bagi tiap variable lebih tinggi daripada 10 persen serta nilai VIF lebih sedikit daripada 10 yang memiliki arti model persamaan regresi bebas daripada multikoleniaritas. Uji heteroskedastisitas memiliki tujuan agar tahu apa didalam model regresi terjadinya ketidaksamaan varians daripada residual satu pengamatan menuju pengamatan lainnya yang dilaksanakan dengan uji Glejser. Bila tak ada satupun variable independen yang mempunyai pengaruh signifikan pada nilai absolute residual ataupun nilai signifikansinya diatas 0,05 jadi tidak adanya terkandung gejala heteroskedastisitas. 
Tabel 8.

Hasil Uji Heteroskedastisitas

\begin{tabular}{|c|c|c|c|c|c|}
\hline \multirow[t]{2}{*}{ Model } & \multicolumn{2}{|c|}{$\begin{array}{l}\text { Unstandardized } \\
\text { Coefficients }\end{array}$} & \multirow{2}{*}{$\begin{array}{c}\text { Standardized } \\
\text { Coefficients } \\
\text { Beta }\end{array}$} & \multirow[t]{2}{*}{$\mathrm{t}$} & \multirow[t]{2}{*}{ Sig. } \\
\hline & $\mathrm{B}$ & Std. Error & & & \\
\hline (Constant) & 1.338 & 1.335 & & 1.002 & .321 \\
\hline $\begin{array}{l}\text { Kepemimpinan } \\
\text { Transformasional }\end{array}$ & 102 & .078 & .233 & 1.306 & .198 \\
\hline Keadilan Organisasi & -.085 & .049 & -.310 & -1.739 & .088 \\
\hline Kepuasan Kerja & .035 & .080 & .073 & .436 & .665 \\
\hline
\end{tabular}

Sumber: Data Diolah, 2018

Tabel 8 menunjukan bahwasannya nilai Sig. daripada variable Kepemimpinan Transformasional sejumlah 0,198, Keadilan Organisasional sejumlah 0,088, serta Kepuasan Kerja sejumlah 0,665. Nilai itu lebih tinggi daripada 0,05 yang memiliki arti tak adanya pengaruh diantara variabel independen pada absolute residual. Dengan demikian, model yang dibentuk tak terkandung gejala heteroskedastisitas. Berdasarkan uraian pada Tabel 6, 7 dan 8 di atas, menunjukkan bahwa semua uji asumsi klasik sudah terpenuhi sehingga hasil analisis regresi layak untuk dibahas lebih lanjut.

Uji ketepatan model regresi bertujuan untuk mengetahui apakah semua variabel bebas yang diidentifikasi (kepemimpinan transformasional, keadilan organisasi, dan kepuasan kerja) tepat digunakan memprediksi komitmen organisasional pegawai. Uji ini sering juga disebut dengan uji $\mathrm{F}$, berdasarkan hasil uji f dapat ditarik kesimpulan yaitu Hasil uji F (Ftest) menunjukkan bahwa besaran signifikansi $\mathrm{P}$ value 0,000 yang lebih sedikit daripada $\alpha=0,05$, berikut memiliki arti model yang dipakai di riset berikut yaitu layak atau tidak. Hasil tersebut memberi arti bahwasannya seluruh variable bebas bisa memberikan prediksi ataupun penjelasan fenomena Komitmen Organisasional karyawan Hotel Puri Saron Seminyak. Hal ini berarti model dapat digunakan untuk analisa lebih 
lanjut atau dengan kata lain model dapat digunakan untuk memproyeksikan karena hasil goodness of fitnya baik dengan nilai signifikansi P value 0,000.

Pengaruh variabel Kepemimpinan Transformasional, Keadilan Organisasi, dan Kepuasan Kerja, terhadap Komitmen Organisasional karyawan yang diuji dengan menggunakan Uji t. Kriteria uji untuk memberi penjelasan interpretasi pengaruh diantara masing-masing variable yaitu apabila nilai signifikansi $<0,05$ jadi $\mathrm{H}_{0}$ ditolak serta $\mathrm{H}_{1}$ diterima. Sebaliknya, bila nilai signifikansi > 0,05 jadi $\mathrm{H}_{0}$ diterima serta $\mathrm{H}_{1}$ ditolak. Berdasar hasil analisis pengaruh Kepemimpinan Transformasional pada Komitmen Organisasional didapatkan nilai Signifikasi sejumlah 0,008 dengan nilai koefisien beta 0,342. Nilai Signifikansi 0,008 $<0,05$ memberikan indikasi bahwasannya $\mathrm{H}_{0}$ ditolak serta $\mathrm{H}_{1}$ diterima. Hasil berikut memiliki arti bahwasannya Kepemimpinan Transformasional memiliki pengaruh positif serta signifikan pada Komitmen Organisasional karyawan Hotel Puri Saron Seminyak.

Berdasar hasil analisis pengaruh Keadilan Organisasi pada Komitmen Organisasional didapatkan nilai signifikansi sejumlah 0,022 dengan nilai koefisien beta 0,293. Besaran Signifikansi 0,022 <0,05 memberikan indikasi bahwasannya $\mathrm{H}_{0}$ ditolak serta $\mathrm{H}_{2}$ diterima. Hasil ini memiliki arti bahwasannya Keadilan Organisasi berpengaruh positif dan signifikan terhadap Komitmen Organisasional karyawan Hotel Puri Saron Seminyak. Berdasar hasil analisis pengaruh Kepuasan Kerja pada Komitmen Organisasional didapatkan nilai signifikansi sejumlah 0,026 dengan nilai koefisien beta 0,265. Nilai signifikansi $0,026<0,05$ memberikan indikasi bahwasannya $\mathrm{H}_{0}$ ditolak serta $\mathrm{H}_{3}$ diterima. Hasil ini 
Putu Yoga Arimbawa, Pengaruh Kepemimpinan Transformasional...

memiliki arti bahwasannya Kepuasan Kerja memiliki pengaruh positif serta signifikan terhadap Komitmen Organisasional karyawan Hotel Puri Saron Seminyak.

Hasil penelitian ini memiliki implikasi teoristis dan praktis. Secara teoristis, hasil penelitian ini menunjukan bahwa kepemimpinan transformasional, keadilan organisasional, dan kepuasan kerja berpengaruh positif dan signifikan terhadap komitmen organisasional. Hasil penelitian ini memberikan dukungan empiris dan dinyatakan memperkuat hasil-hasil studi penelitian terdahulu. Secara praktis, penelitian ini diharapkan memberikan manfaat bagi pimpinan dan karyawan Hotel Puri Saron Seminyak. Pimpinan dengan kepemimpinan transformasional diharapkan dapat menyampaikan tujuan dari organisasi dengan jelas agar dapat meningkatkan komitmen organisasional karyawan Hotel Puri Saron Seminyak. Manajemen Hotel Puri Saron Seminyak agar selalu menerapkan prosedur kerja yang adil, karena dengan keadilan tersebut komitmen organisasional karyawan Hotel Puri Saron akan meningkat. Menjalin hubungan kerja yang baik antar karyawan Hotel Puri Saron Seminyak merupakan hal dalam terciptanya kepuasan kerja yang dimana dengan kepuasan kerja yang baik maka akan meningkatkan komitmen organisasional karyawan di Hotel Puri Saron Seminyak.

Pada pembuatan riset berikut, penulis menemukan kesadaran masihlah sangatlah jauh didalam kata sempurna serta mempunyai banyaknya keterbatasan yang mungkin dapat memberikan pengaruh hasil yang diinginkan, oleh karena hal tersebut keterbatasan ini diharap mampu lebih diberikan perhatian bagi penelitipeneliti selanjutnya, dimana kelemahan-kelemahan yang ditemukan peneliti 
adalah, lokasi penelitian ini dilakukan di bidang perhotelan dimana sudah banyak penelitian mengenai komitmen organisasional dilakukan di bidang perhotelan dan Informasi yang diberi responden lewat kuisioner terkadang tak menunjukkan saran responden yang sebenarnya dikarenakan perbedaan seseorang dalam mempresepsikan sesuatu, sehingga rentan terjadi pembiasan dari jawaban responden.

\section{SIMPULAN DAN SARAN}

Simpulan yang dapat diambil berdasarkan hasil analisis penelitian ini adalah sebagai berikut. 1) Kepemimpinan transformasional berpengaruh positif dan signifikan terhadap komitmen organisasional karyawan di Hotel Puri Saron Seminyak, artinya semakin baik penerapan kepemimpinan transformasional maka semakin tinggi tingkat komitmen organisasional karyawan di Hotel Puri Saron Seminyak. 2) Keadilan organisasional berpengaruh positif dan signifikan terhadap karyawandi Hotel Puri Saron Seminyak, artinya pelaksanaan keadilan organisasional yang baik maka semakin tinggi tingkat komitmen organisasional karyawan di Hotel Puri Saron Seminyak. 3) Kepuasan Kerja berpengaruh positif dan signifikan terhadap komitmen organisasional karyawan di Hotel Puri Saron Seminyak, artinya semakin tinggi tingkat kepuasan kerja yang dirasakan karyawan maka semakin tinggi tinggi komitmen organisasional karyawan di Hotel Puri Saron Seminyak.

Saran yang dapat diberikan berdasarkan hasil penelitian ini adalah sebagai berikut. 1) Saran bagi pimpinan Hotel Puri Saron Seminyak untuk membangkitkan kreatifitas karyawan dalam melakukan pekerjaan dengan cara, 
Putu Yoga Arimbawa, Pengaruh Kepemimpinan Transformasional...

memberikan kepercayaan kepada karyawan untuk menyelesaikan pekerjaannya, karena dengan hal tersebut karyawan akan merasa nyaman didalam melakukan pekerjaan dan mengakibatkan karyawan akan lebih berkomitmen dangan perusahaan. 2) Manajemen Hotel Puri Saron Seminyak perlu memberikan kesempatan yang sama bagi seluruh karyawan untuk ikut dalam pengambilan keputusan. Adapun saran yang dapat dilakukan dengan cara mengadakan rapat kecil di masing-masing divisi, menyediakan kotak saran bagi karyawan atau juga bisa turun langsung ke lapangan dan melakukan perbincangan kecil dengan karyawan untuk mengumpulkan informasi atau aspirasi yang ingin disampaikan karyawan. 3) Kepuasan kerja karyawan atas respon pimpinan dalam menangani masalah yang dihadapi karyawan sangat penting adanya guna meningkatkan komitmen organisasional. Saran bagi pemimpin dalam menangani masalah yang dihadapi karyawan dengan pimpinan harus sigap dalam menanggapi masalah yang dihadapi karyawan di tempat kerja agar karyawan merasa puas dan berdampak pada meningkatnya komitmen organisasional karyawan.

\section{REFERENSI}

Adiapsari, Retno. (2014). Analisis pengaruh iklim organisasi terhadap komitmen dengan kepuasan kerja sebagai variabel mediasi pada karyawan PT. Tiga Serangkai Solo. Riset Manajemen dan Akuntansi. 3(5) : 75-102.

Al-Zu'bi, H. A.(2013). A study of relationship between organizational justice and job satisfaction. International Journal of Business and Management. 5(12) : 102-109.

Akanbi., Paul Ayobami Ofoegbu., Onyema., E. (2013). Impact of Perceived Organizational Justice on Organizational Commitment of a Food and Beverage Firm in Nigeria. International Journal of Humanities and Social Science. 3 (14) : $207-218$.

Antonakis, J., Avolio, B.J., and Sivasubramaniam, N. (2003). Context and Leadership: An Examination of the Nine Factor Full-Range Leadership 
Theory Using the Multifactor Leadership Questionnaire, The Leadership Quarterly. 14(2) : 261-295.

Astuti Endang Siti, Kusdi Raharjo and Djamhur Hamid. (2013). The Effect of Empowerment of The Organizational Commitment and The Job Satisfaction of The Employees of The National Electicity Company (Ltd). Asian Transaction On Basic \& Applied Science. 3(4) :2221-4291.

Azman, Ismail, Hasan Al-Banna. M., Sulaiman. A, Z., Mohamad. M. H., and Munirah. H. Y. (2014). An Empirical Study of the Relationship between Transformational Leadership, Empowerment and Organizational Commitment. Business and Economic Research Journal. 2(1) : 89-107.

Bakhshi, A., Kuldeep, K., Rani, E. (2013). Oragnizational justice Perception as Predictor of Job Satisfaction and Organizational Commitment. International Journal of Business and Management. 4(9) :145-154.

Bass, B. M. (1997). Does Transactional - Tranfomational Leadership Paradigm Transcend Organizational and National Boundaries. Journal American Psychologist, 52 :130-139.

Bettencourt, Lance A., Stephen W. Brown Scott., and B MacKenzie. (2015). Customer-oriented boundary-spanning behaviors: Test of a social exchange model of antecedents. Journal of Retailing. 81 (2) : 141 - 157.

Bushra, Fatima, Usman, A., and Naveed, A. (2013). Effect of Transformationl Leadership on Employees' Job Satisfaction and Organizational Commitment in Banking Sector of Lahore (Pakistan). Intenational Journal Business and Social Science, 2(18) : 261-267.

Dehkordi, F.R., Sardar, M., dan Yektayar, M. (2013). Relationship of organizational justice and organizational commitment of the staff in General Directorate of Youth and Sports in Chahar Mahal Va Bakhtiari Province. European Journal of Experimental Biology. 3(3) : 696-700.

Desianty, Sovyia. (2015). Pengaruh Gaya Kepemimpinan Terhadap Komitmen Organisasi pada Pt Pos Indonesia (Persero) Semarang. Jurnal Studi Manajemen \& Organisasi, 2(1) : 69-84.

Dockel, Andreas. (2016). The effect of retention factors on organizational commitment: an investigation of high technology employee. SA Journal of Human Resource Management, 4(28) : 20-28.

Farzin, F., Reza, and Jirdehi. (2013). Organizational Justice, Employees Trust and Organizational Support. Kuwait Capter of Arabian Journal of Business and Management Review. 3(2) : 74-85. 
Ghaziani, F.G., Safania. A., Tayebi. S.M. (2012). Impact of Organizational Justice Perceptions on Job Satisfaction and Organizational Commitment: the Iran's Ministry of Sport Perspective. Australian Journal of Basic and Applied Sciences, 6(7) : 179-188.

Ghozali, Imam. (2012). Aplikasi Analisis Multivariate dengan Program IBM SPSS 20. UNDIP : Semarang.

Ghozali, Imam. (2014). Aplikasi Analisis Multivariate dengan program SPSS. Universitas Diponegoro: Semarang.

Gibson, J. L., Donnelly, J. H., Ivancevich, J. M., Konopaske, R. (2012). Organizations:Behavior, structure, processes. Singapore: McGraw-Hill.

Handoko, H. (2005). Manajemen Sumber Daya Manusia dan Personalia. Yogyakarta: BPFE UGM.

Haq, Muhamad Anwar UI, Yan Jindong, Nazar Hussain, Zafar Uz Zaman Anjum. (2014). Factor Affecting Organizational Commitment Among Bank In Pakistan. Journal Business and Management, 16(4) : 18-24.

Hidayat, R. (2013). Pengaruh Kepemimpinan terhadap Komunikasi, Kepuasan Kerja, dan Komitmen Organisasi pada Industri Perbankan. Makara Seri Sosial Humaniora. 17(1) :19-32.

Huges, R.L., Ginnet, R.C., and Curphy, G.J. (2012). Leadership : Memperkaya pelajaran dari pengalaman, Edisi Ketujuh, Jakarta : Salemba Empat.

Indrawan, Dewa Cahyadi dan A.A. Sagung Kartika Dewi. (2014). Pengaruh kompensasi, kepemimpinan, dan lingkungan kerja fisik terhadap kepuasan kerja karyawan PT Cargo Asas International, Denpasar. E-Jurnal Manajemen Universitas Udayana. 3(6) : 1767-1779.

Ismail, A., Mohamad, M.H., Mohamed, H.A., Rafiuddin, N.M, Zhen, K.W.P. (2013). Transformational and Transactional Leadership Styles as a Predictor of Individual Outcomes. Theoretical and Applied Economics. 17(6) : 89104.

Jandaghi, Gholamreza, Hassan Zareei Martin, and Ali Farjami. (2014). Comparing Tranformational Leader ship in Successful and Unsuccessful Companies. The Journal of International Social Research, 2(6) : 356-376.

Jawad.M., Raja.S., Abraiz.A., Tabassum.T.M. (2012). Role of Organizational justice in organizational commitment with moderating effect of employee work attitudes. Journal of Business and Management. 5(4) : 39-45. 
Junaedi, Deddy, Bambang Swasto, dan Hamidah Nayati Utami. (2013). Pengaruh Gaya Kepemimpinan, Keselamatan Kerja dan Kesehatan Kerja, Kepuasan Kerja Terhadap Komitmen Organisaional. Jurnal Profit, 7(1) : 127-136.

Karakus, M., Mehmet U., and Mustafa., T. (2014). Two alternative models on the relationships between organizational justice, organizational commitment, burnout, and job satisfaction of education supervisors. KEDI Journal of Educational Policy. 11 (1) : 69 - 94.

Karambut, Christien A., Eka Afnan T., dan Noormijati. (2014). Analisis Pengaruh Kecerdasan Emosional, Stres Kerja Dan Kepuasan Kerja Terhadap Komitmen Organisasional (Studi Pada Perawat Unit Rawat Inap RS Pati Waluya Malang). Jurnal Aplikasi Manajemen. 10(3) : 655-668.

Karim, Faisal dan Omar Rehman. (2012). Impact Of Job Satisfaction, Perceived Organizational Justice And Employee Empowerment On Organizational Commitment In Semi Government Organizations Of Pakistan. Journal of Business Studies Quarterly, 3(4) : 92-104.

Khan, Z., Shahzad, K., and Saqib, S. (2013). Moderating Role of Procedural Justice Empowerment in Transformational Leadership with Impact on Organizational Commitment. International Review of Management and Business Research. 2(3) : 847:852.

Kristanto, H. (2015). Keadilan organisasional, komitmen organisasional, dan kinerja karyawan. Jurnal Manajemen dan Kewirausahaan. 17(1), : 86-98.

Lumley, E.J. Coetzee, M. Tladinyane, R. Ferreira, N. (2014). Exploring the jobsatisfaction and organisational commitment of employees in theinformation technology environment Outhern. African Business Review. (15)1: 889-978.

Luthans, Fred. (2006). Organizational Behavior, Third Edition. The McGraw-Hill Companies Inc., New York.

Maulizar. Said Musnadi dan Muklis Yunus. (2013). Pengaruh Kepemimpinan Transaksional dan Transformasional Terhadap Kinerja Karyawan Bank Syariah Mandiri Cabang Banda. Jurnal Manajemen Pascasarjana Universitas Syiah Kuala. 1(1) : 58-65.

Meyer, J., and Allen, N. (1991). A three-component conceptualization of organizational commitment. Human Resource Management Review. 1(1) : 61-89.

Meyer, John P. Herscovith L. (2014). Commitment in the workplace : toward general model. Human Resource Management Review. 11 : 299-326. 
Naeem, Ayesha T., Freedha Ihsan dan Zahid Mahmood. (2014). The Study of Organizational Justice, Violation of Psychological Contract and its Effect on Job Satisfaction in Paints Industry of Pakistan. International Journal of Academic Research in Business and Social Sciences. 4(12) : 244-251.

Naqvi, S.A.H., Hashmi, M.A., Raza S.A., Zeeshan, A. ve Shaikh, F.F. (2013). Impact of Supportive Leadership and Organizational Learning Culture as a Moderator On The Relationship of Psychological Empowerment and Organizational Commitment. Australian Journal of Business and Management Research, 1(8) : 65-71.

Ngadiman, Eliyana, A., dan Rahmawari, D. (2013). Influence Transformational Leadership and Organization Climate to the Work Satisfaction, Organizational Commitment and Organizational Citizenship Behavior on the Educational Personnel of Sebelas Maret University, Surakarta. Eroupan Journal of Business and Management, 5(10) : 97-114.

Njoroge. D., Gachunga. H., Kihoro. J. (2015). Transformational Leadership Style And Organizational Commitment: The Moderating Effect Of Employee Participation. The Strategic Journal of Business \& Change Management. 2 (6). pp. $94-107$.

Pradhiptya, A R. (2013). Pengaruh kepuasan kerja terhadap organizational citizenship behavior (OCB) dengan mediasi komitmen organisasional. Jurnal Ilmu Manajemen. 1(1) : 342-352.

Puspitawati, Ni Made Dwi., dan I Gede Riana. (2014). Pengaruh Kepuasan Kerja Terhadap Komitmen Organisasional dan Kualitas Layanan. Jurnal Manajemen Strategi Bisnis dan Kewirausahaan. 8(1) : 69-80.

Rae, K. (2013). Perceptions Of Empowerment and Commitment Affect Job Satisfaction: A Study of Managerial Level Effects. Accounting Accountability \& Performance. 18(1).

Robbins, S.P dan T.A Judge. (2008). Perilaku Organisasi. Jakarta: Salemba Empat.

Safitri, I.P. Wahyu, R., Kusdi. Djudi, M. (2014). Analisis Pebedaan Komitmen Organisasi Berdasarkan Status Karyawan (Studi Pada Karyawan PT. Kobexindo Tractors Tbk. Representative Office Bengkulu). Jurnal Administrasi Bisnis. 10(1) : 215-239

Shurbagi, Adel Mohamed Ali. (2014). The Relationship Between Transformational Leadership Style Job Satisfaction and the Effect of Organizational Commitment. Journal International Business. 7 (11) : 126 138. 
Steer, R.M dan Porter, L.W. (1983). Motivation and Work Behavior. McGrawHill. New York.

Sugiyono. (2014). Metode Penelitian Bisnis. Bandung: CV. Alfabeta.

Surbakti, (2013). Analisis Pengaruh Kepemimpinan Transformasional dan Motivasi terhadap Kinerja Karyawan: Studi pada PT. Kereta Api Indonesia Dap IV Semarang. Jurnal Fakultas Ekonomi Universitas Diponegoro Semarang. (1)1: 55-67.

Surya, M., dan Rendy. (2013). Analisa Komitmen Organisasi Karyawan Castello Café \& Lounge. Jurnal Hospitality dan Manajemen Jasa. 1(2) : 503-513.

Sutrisna, I W. W. dan Agoes Ganesha Rahyuda. (2014). Pengaruh Keadilan Distributif, Prosedural, dan Interaksional Terhadap Kepuasan Kerja dan Komitmen Organisasi Pada Paramedis di Rumah Sakit Tk II Udayana Denpasar. E-Jurnal Manajemen Udayana, 3 (9) : 2489-2509.

Tejada and Joyce Raymond. (2014). On the Misue of Slovin's Formula. The Philippine Statistican Punzalan University of the Philippine Diliman. 61(1) : 129-136

Thamrin, M.H. (2012). The Influence of Transformational Leadership and Organizational Commitment on Job Satisfaction and Empoyee Performance. International Journal of Innovation, Management and Technology, 3(5) : 566-572.

Top, M., Akdere, M., Tarcan, M. (2014). Examining transformational leadership, job satisfaction, organizational commitment and organizational trust in Turkish hospitals: public servants versus private sector employees. The International Journal of Human Resource Management. 26(9) : 1-24.

Voon, M.L., Lo, M.C., Ngui, K.S., \& Ayob, N.B. (2015). The influence of leadership styles on employee job satisfaction in public sector organization Malaysia. International Journal of Business, Management and Social Sciences, 2(1) : 24-32.

Wibowo. (2012). Manajemen Kinerja. Edisike 3. Jakarta: Rajawali Pers.

Wirawan, Nata. (2014). Cara Mudah Memahami Statistika Ekonomi dan Bisnis. Denpasar:Keraras Emas.

Woszczyna, Katarzyna Szczepanska. (2015). Leadership and Organizational Culture as the Normative Influence of Top Management on Employees Behavior in the Innovation Process. Journal of Business Economics nad Management, 34 : 396-402. 